\title{
OSSEOINTEGRATION SPECIFIED GRIT BLASTING PARAMETERS
}

\author{
Alexandra Kemény ${ }^{1}$, István Hajdu ${ }^{1}$, Dóra Károly ${ }^{1}$, Dávid Pammer ${ }^{1}$ \\ 1 Budapest University of Technology and Economics, Faculty of Mechanical Engineering, Department \\ of Materials Science and Engineering, H-1111 Budapest, XI. Bertalan Lajos u. 7. Building MT, \\ Hungary. E-mails: alexandra.kemeny@edu.bme.hu, hajdu999@gmail.com, kdora@eik.bme.hu, \\ pammer@eik.bme.hu
}

\section{Introduction}

Nowadays, it is very common to have spinal diseases such as scoliosis. When the curve of the spine reaches a certain deformation, it can only be healed by surgery. These implants are staying in the patient forever.

The osseointegration is a complex process. First, the implant needs to have a direct interaction with the bone. If the implantation is successful, and the surface of the implant is suitable for osteoblasts, these cells start forming new bone. This creates a strong bond between the bone and the implant [1].

There are plenty of dental implants and hip prosthesis femoral stems on the market with grit blasted surfaces and great results in patients. Grit blasting creates a micrometer roughness which stimulates osteoblasts [2]. However spinal implants' surfaces are not yet treated this way.

Some researches already shown that grit blasted spinal implants needed twice the torque to remove from sheep vertebrae in vivo, twelve weeks after implantation that the smooth screws [3]. Other research has shown, that the success of an implant is highly dependent of the surface characteristics, and also the macro design of the implant. Surface microroughness has been well established to achieve better osseointegration [1].

Implant materials can be very diverse. In implantology the most widespread material nowadays is the titanium and its alloys, because of its great biocompatibility and mechanical properties [4]. Grit blasting is a surface modification treatment. The morphology of the surface changes significantly as the small particles hit the implant with high speed [5].

The purpose of our research is to optimize the blasting parameters on disks and then do the surface treatment on the spine implants.

\section{Materials and methods}

In the research, we examined implants and disks made of Ti 6Al 4V ELI, also known as Grade23 Titanium. For the chemical composition see Tab. 1. This alloy is a bioinert material, so it has a stable oxide film on its surface which provides corrosion resistance and biocompatibility [4].

\begin{tabular}{|c|c|c|c|c|}
\hline $\mathbf{C} \%$ & Al \% & $\mathbf{N} \%$ & $\mathbf{O} \%$ & Ti \\
\hline$\leq 0.08$ & 5.5 to 6.5 & $\leq 0.03$ & $\leq 0.13$ & Balance \\
\hline Fe \% & $\mathbf{V} \%$ & $\mathbf{H} \%$ & \multicolumn{2}{|c|}{ Other \% } \\
\hline$\leq 0.25$ & 3.5 to 4.5 & $\leq 0.013$ & \multicolumn{2}{|c|}{$\leq 0.40$} \\
\hline
\end{tabular}

Tab. 1. Ti $6 \mathrm{Al} 4 \mathrm{~V}$ chemical composition

As blasting material alumina powder was used. The following five technological parameters of the sandblasting were investigated: size of blasting material, distance between the tip of the blasting pen and the samples, time, pressure and angle of the blasting pen and the axis of samples. Each parameter was tested in three different levels.

In total 135 disks and 6 implants were used in the experiment. The disks were $1.5 \mathrm{~mm}$ in thickness and $5.5 \mathrm{~mm}$ in diameter.

For the blasting process a clamping device was needed which helped to fix the disks during blasting. With this the angle and the distance was adjustable during the blasting process. To calculate the effect of parameters to the surface roughness, Minitab 17 statistical software was used.

After blasting the surface roughness (Ra) was investigated. For this measurement, a Mahr Pocket Surf IV profilometer was used. Olympus SZX16 stereomicroscope and Philips XL30 scanning electron microscope was used for taking images.

\section{Results}

The ideal surface roughness to osseointegration is between 1-2 $\mu \mathrm{m}$ [6]. Based on the experiments 1.5 $\mu \mathrm{m}$ roughness can be created on Grade 23 Ti disks 


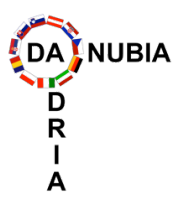

34th Danubia-Adria Symposium on Advances in Experimental Mechanics

University of Trieste, Italy, 2017
(Fig.1.) with the following parameters: particle size of $354-500 \mu \mathrm{m}$, time of $30 \mathrm{~s}$, pressure of $4 \mathrm{bar}$, distance of $20 \mathrm{~mm}$ and angle of $75^{\circ}$.

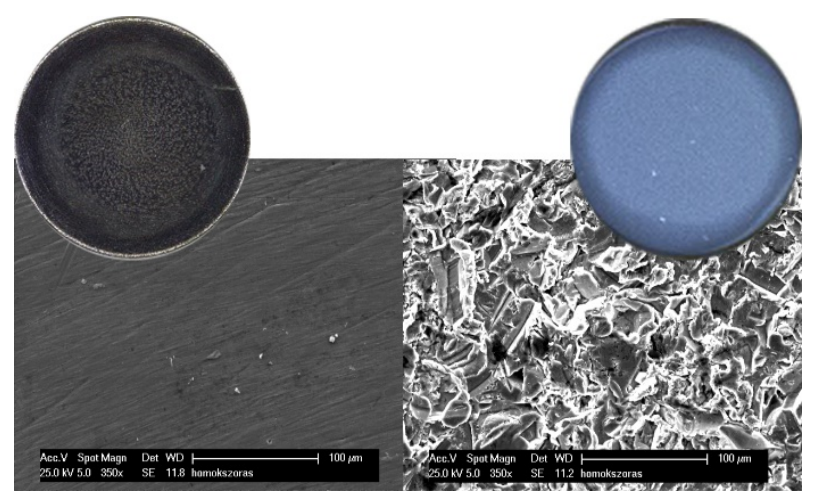

Fig. 1. Stereomicroscopic and SEM image of a disk before (left) and after (right) blasting

Using the mentioned blasting parameters, a consistent rough surface was reached with a treatment specific morphology on the implants, see Fig. 2.

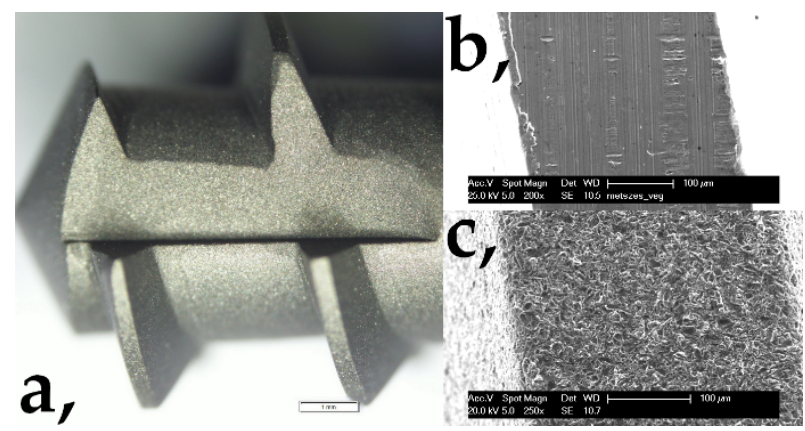

Fig. 2. Stereomicroscopic image of the blasted implant (a) and SEM images before (b) and after (c) blasting

The results show that of the five investigated parameters the size of blasting material has the biggest influence on the surface roughness. This follows the pressure the other three parameters are negligible, see Fig. 3.

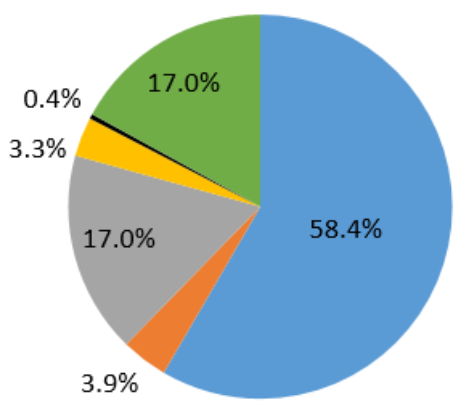

- Grit size (58.4\%)

Time $(3.9 \%)$

- Pressure $(17.0 \%)$

Distance (3.3\%)

- Angle $(0.4 \%)$

Error (17.0\%)

\section{Remarks}

- With $354-500 \mu \mathrm{m}$ particle size, $30 \mathrm{~s}$ blasting time, $75^{\circ}$ blasting angle, 4 bar pressure and 20 $\mathrm{mm}$ blasting distance, the $1.5 \mu \mathrm{m}$ surface roughness can be created on machined Grande23 Ti disks and implants.

- This experiment processes an important matter in material science, because the osseointegration of the mentioned surface roughness is far better.

\section{Acknowledgements}

The publication of the work reported herein has been supported by ETDB at BME.

\section{References}

[1] Rolando A. Gittens et al., Implant osseointegration and the role of microroughness and nanostructures: Lessons for spine implants, Acta Biomaterialia 10, 2014. pp. 3363-3371.

[2] Rene Olivares-Navarrete, DDS, PhD et al., Rough titanium alloys regulate osteoblast production of angiogenic factors, The Spine Journal 13, 2013. pp. 1563-1570.

[3] Zvi Schwartz et al., Effect of MicrometerScale Roughness of the Surface of Ti6Al4V Pedicle Screws in Vitro and in Vivo, The Journal of Bone and Joint Surgery Vol. 90A No.11, 2008. pp. 2485-2498.

[4] D.M. Brunette et al., Titanium in medicine: Material Science, Surface Science, Engineering, Biological Responses and Medical Applications, Springer Science \& Business Media, 2001. ISBN 978-3-64256486-4.

[5] Xuanyong Liu et al., Surface modification of titanium, titanium alloys, and related materials for biomedical applications, Materials Science and Engineering R47, 2004. pp. 49-121.

[6] T. Albrektsson, A. Wennerberg, Effects of titanium surface topography on bone integration: a systematic review, Clinical Oral Implants Research, vol. 20 (4), 2009, pp. 172184.

Fig. 3. Effects of the five technological parameters to the surface roughness 